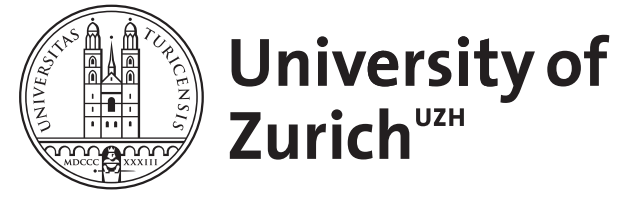

Bridging diversity in organizations and cross-cultural work psychology by studying perceived differences

Shemla, Meir ; Meyer, Bertolt

DOI: https://doi.org/10.1111/j.1754-9434.2012.01464.x

Posted at the Zurich Open Repository and Archive, University of Zurich ZORA URL: https://doi.org/10.5167/uzh-154528

Journal Article

Published Version

Originally published at:

Shemla, Meir; Meyer, Bertolt (2012). Bridging diversity in organizations and cross-cultural work psychology by studying perceived differences. Industrial and Organizational Psychology, 5(3):370-372.

DOI: https://doi.org/10.1111/j.1754-9434.2012.01464.x 


\section{Bridging Diversity in Organizations and Cross-Cultural Work Psychology by Studying Perceived Differences}

\author{
MEIR SHEMLA \\ Technische Universität Dresden \\ BERTOLT MEYER \\ Universität Zürich
}

By exploring the links between diversity and cross-cultural work psychology, Ferdman and Sagiv (2012) shed light on a fundamental question at the heart of diversity research: What do we mean by "diversity"? As the authors highlight, "depending on what we mean by 'diversity,' we may be looking at different phenomena" altogether. Quite rightly, the authors point out that different cultures hold different views on heterogeneity. In this commentary, we would like to extend the propositions for how the two fields might benefit from each other by adding another possible bridge: the study of perceived differences.

Indeed, the meaning of diversity may be contingent upon several factors. First, conceptualizations of diversity in previous research vary with respect to how narrowly or broadly this construct was defined. Specifically, the diversity construct has been

Correspondence concerning this article should be addressed to Meir Shemla.

E-mail: shemla@psychologie.tu-dresden.de

Address: Work and Organizational Psychology, Technische Universität Dresden, Zellescher weg 17, 01062 Dresden, Germany used in the literature to describe a wideranging spectrum of differences, from as specific as gender composition of a group to as broad and inclusive as deep-level dissimilarities. Second, as Ferdman and Sagiv point out in their summary of the literature, "diversity does not function equally across attributes." For instance, differences with respect to age may carry different psychological significance and exert different impact on groups than culture differences. Finally, and most relevant to this comment, the significance, meaning, and manifestation of diversity are likely to vary across cultures. For example, whereas in liberal cultures religion diversity is less likely to be salient, this type of diversity is probable to play a critical role in determining the functioning of groups in more conservative and religious cultures.

Clearly, inability to assign the concept of diversity a consistent and universal meaning sets obstacles for theoretical and practical advances. Ferdman and Sagiv mention several attempts to classify and define different diversity types (e.g., distinguishing between different forms of within-unit 
distribution such as separation, variety, and disparity, as suggested by Harrison and Klein, 2007) but criticize that conclusions based on specific categories of diversity are too general and do not focus on a specific dimension. The problem here is that there is an infinite number of attributes that can constitute diversity and that those may carry different meanings across different cultures. Accordingly, recent meta-analytic findings (Bell, Villado, Lukasik, Belau, \& Briggs, 2011; Guillaume, Brodbeck, \& Riketta, 2012) remain inconclusive about the utility of such diversity classifications. However, all the different classifications of diversity that Ferdman and Sagiv mention refer to actual or objective diversity attributes. We posit that a possible answer, if imperfect, to the need to clarify the psychological and cultural meaning of diversity across diversity attributes, groups, and time can be found in investigating subjective perceptions of diversity.

\section{Subjective Diversity}

Subjective diversity assesses the extent to which group members perceive their team to be diverse. Importantly, subjective diversity measures do not necessitate a reference to any specific attribute of diversity and may not necessarily be a direct result of any specific objective diversity attribute. Instead, it assesses the global perception of diversity across the limitless dimensions of diversity that exist in any team (Oosterhof, Van der Vegt, Van de Vliert, Sanders, \& Kiers, 2009) and the degree to which team members perceive their team to be split into subgroups. An example use of this type of diversity measure is found in a recent paper by Jehn and Bezrukova (2010), who asked participants to rate the degree to which their team was split into subgroups, broken into alliances, and divided into subsets of individuals.

Diversity perceptions are shaped by an interaction between actual objective differences and the cultural and interindividual differences in the construal of diversity. For example, Homan, Greer, Jehn, and Koning
(2010) showed that identical team configurations could be perceived differently based on individuals' diversity beliefs. Similarly, Ooserhof et al. (2009; see also Meyer, Shemla, \& Schermuly, 2011) showed that individuals use a myriad of idiosyncratic categories in their perception of dissimilarities at the workplace. As the organizational setting shapes perceptions of diversity, subjective perceptions of diversity also provide a possibility to integrate the organizational context into diversity research.

With respect to the issue of defining diversity across cultures, contexts, and diversity dimensions, subjective diversity offers several advantages over objective diversity. First, measuring objective levels of diversity (based on, for example, the team members' age or educational specialization) is problematic insofar as it assumes that team members indeed perceive those compositional aspects to be salient or relevant. In contrast, measuring diversity using subjective perceptions of group members avoids the need to presuppose that certain dimensions of differences are indeed relevant to the specific unit, context, or culture. Further, in contrast to objective diversity measures, subjective diversity also does not require choosing among narrower or broader dimensions. Second, as pointed out above, one of the major problems associated with objective diversity measures is the inability to discern effectively among the variety of diversity attributes. In different cultures, different attributes are likely to carry different psychological meaning and exert dissimilar impact on groups. Subjective diversity measures overcome this obstacle by providing the possibility to assign a comparable psychological weight to diversity attributes that are qualitatively different from each other.

In sum, we propose that instead of studying objective features of the environment, the results of its perception should be studied because such perceptions may be more proximal in explaining actual behavior (Harrison \& Klein, 2007). Culture partly shapes how diversity is perceived, and 
these perceptions govern its effects. We thus believe that the study of perceived within-unit differences constitutes a further promising and viable bridge between cross-cultural psychology and the study of diversity in organizations.

\section{References}

Bell, S., Villado, A., Lukasik, M., Belau, L., \& Briggs, A. (2011). Getting specific about demographic diversity variable and team performance relationships: A meta-analysis. Journal of Management, 37, 709-743. doi:10.1177/0149206310365001

Ferdman, B. M., \& Sagiv, L. (2012). Diversity in organizations and cross-cultural work psychology: What if they were more connected? Industrial and Organizational Psychology: Perspectives on Science and Practice., 5, 323-345.

Guillaume, Y., Brodbeck, F., \& Riketta, M. (2012). Surface- and deep-level dissimilarity effects on social integration and individual effectiveness related outcomes in work groups: A metaanalytic integration. Journal of Occupational and Organizational Psychology, 85, 80-115. doi:10.1111/j.2044-8325.2010.02005.x
Harrison, D. A., \& Klein, K. J. (2007). What's the difference? Diversity constructs as separation, variety, or disparity in organizations. Academy of Management Review, 32, 1199-1228. doi:10.5465/ AMR.2007.26586096

Homan, A. C., Greer, L. L., Jehn, K. A., \& Koning, L. (2010). Believing shapes seeing: The impact of diversity beliefs on the construal of group composition. Group Processes \& Intergroup Relations, 13, 477-493. doi:10.1177/136843020 9350747

Jehn, K. A., \& Bezrukova, K. (2010). The faultline activation process and the effects of activated faultlines on coalition formation, conflict, and group outcomes. Organizational Behavior and Human Decision Processes, 112, 24-42. doi:10.1016/j.obhdp.2009.11.008

Meyer, B., Shemla, M., \& Schermuly, C. C. (2011). Social category salience moderates the effect of diversity faultlines on information elaboration. Small Group Research, 42, 257-282. doi:10.1177/ 1046496411398396

Oosterhof, A., Van der Vegt, G. S., Van de Vliert, E., Sanders, K., \& Kiers, H. A. L. (2009). What's the difference? Insider perspectives on the importance, content, and meaning of interpersonal differences. Journal of Occupational and Organizational Psychology, 82, 617-637. doi:10.1348/ 096317908X342909 